\title{
Effect of Catalyst Preparation on the Selective Hydrogenation of Biphenol over Pd/C Catalysts
}

\author{
Hong-Baek Cho, Jai-Hyun Park, Bum-Eui Hong, and Yeung-Ho Park \\ Diwision of Aaterials and Chemical Engineering, Hanvang Lniversity, Ansan, Gyeonggi $+25-791$, Korea \\ ${ }^{*}$ E-mail: parhwahthanang.ack $\mathrm{kr}$ \\ Received September 5, 2007
}

\begin{abstract}
The effects of catalyst preparation on the reaction route and the mechanism of biphenol (BP) hydrogenation. which consists of a long series-reaction, were studied. $\mathrm{Pd} / \mathrm{C}$ catalysts were prepared by incipient wetness method and precipitation and deposition method. The reaction behaviors of the prepared catalysts and a commercial catalyst along with the final product distributions were very different. The choice of the catalyst preparation conditions during precipitation and deposition including the temperature. $\mathrm{pH}$. precursor addition rate and reducing agent also had significant effects. The reaction behaviors of the catalysts were interpreted in terms of catalyst particle size. metal distribution, and support acidities.
\end{abstract}

Key Words : Biphenol hydrogenation. Pd/C preparation, Precipitation and deposition. Catalyst particle size. Metal distribution

\section{Introduction}

Bicyclohexyl-4.4'-diol (BHD). 4-4'-(hydroxyl-cyclohexyl)-phenol (HCP). and bicyclohexyl-4.4'-dione (BHDN) are produced in the selective hydrogenation of biphenol (BP) and are of importance in the manufacturing of fine chemicals. particularly with respect to pharmaceuticals. liquid crystal display (LCD), and surfactants. 1.2 BHD is obtained from total hydrogenation of $\mathrm{BP}$ and is composed of three BHD isomers of trans,trans cis,trans. and cis,cis types. HCP and BHDN are obtained from partial hy'drogenation of $\mathrm{BP}$. Therefore. the conditions for hydrogenation of BP are critical to increase the selectivity to desired compounds.

The first report on the preparation of BHD was made by Wilds et al.. who performed hydrogenation of BP to produce BHD over an Ni catalyst. " Among the related patents. Noboru compared various type of catalysts for the production of BHDN by BP hydrogenation. ${ }^{l}$ and Yasushi prepared an alkali-promoted Pd cataly'st for the production of BHDN by $\mathrm{BP}$ hy'drogenation. " A reaction mechanism of $\mathrm{BP}$ hydrogenation was suggested by our group. where the $\mathrm{C}=\dot{\mathrm{O}}$ and $\mathrm{C}=\mathrm{C}$ bond hy'drogenations were found to be the major reactions. ${ }^{4}$ The bottleneck process during $\mathrm{BP}$ hy'drogenation. $\mathrm{C}=\mathrm{O}$ bond hydrogenation, was enhanced with Na promotion on the catalyst. Hýdrogenation of BP to BHD is a long process and. therefore. it is rather difficult to control all the steps of the reactions to get BHD with high purity and yield. Therefore. it is important to understand the effects of catalyst preparation parameters on each step of the long seriesreaction in $\mathrm{BP}$ hydrogenation.

This study was done to find the effects of catalyst preparation methods on the selective hydrogenation of BP. The catalytic effects on the initial conversion of BP and the change of product selectivity were investigated. The catalysts were prepared by incipient wetness method (IW) or precipitation and deposition method (PD). The performance of the catalysts prepared by these methods was compared with that of a commercial $\mathrm{Pd} / \mathrm{C}$ catalyst. Among prepared catalysts. the catalysts prepared from PD were prepared under various conditions including the preparation temperature. $\mathrm{pH}$. dropping rate of $\mathrm{H}_{2} \mathrm{PdCl}_{4}$ solution, and reducing agent. The effects of these parameters on reaction behavior were also studied.

\section{Experimental Section}

Support. Activated carbon from Aldrich (Dcrco-60, surface area of $1.305 \mathrm{~m}^{2} / \mathrm{g}$. pore volume of $1.04 \mathrm{~mL} / \mathrm{g}$ was used for the preparation of $\mathrm{Pd} / \mathrm{C}$ cataly'sts.

Catalyst preparation. $\mathrm{Pd} / \mathrm{C}$ catalysts were prepared using IW and PD methods while changing the preparation parameters. $\mathrm{Pd} / \mathrm{C}(5 \mathrm{wt} \% \mathrm{Pd}$ ) of commercial origin (Kawaken Fine Chemical Co.) was oven-dried at $100^{\circ} \mathrm{C}$ for 2 hours before use. The catalytic performances of the prepared and commercial cataly'sts were compared.

1) Incipient wetness method (IW): $\mathrm{A} \mathrm{H}_{2} \mathrm{PdCl}_{4}$ solution was prepared by dissolving $0.833 \mathrm{~g} \mathrm{PdCl}_{2}$ in $7 \mathrm{~mL}$ of a $3 \mathrm{M}$ $\mathrm{HCl}$ solution. dropping the $\mathrm{H}_{2} \mathrm{PdCl}_{4}$ solution slowly into the activated carbon $(9.5 \mathrm{~g})$ solution, stirring. and drying at 100 ${ }^{\circ} \mathrm{C}$ for 2 hours. The dried cataly st was stored in a desiccator after reduction at $100^{\circ} \mathrm{C}$ under $50 \mathrm{~mL} / \mathrm{min}$ of $\mathrm{H}_{2}(\mathrm{~g})$.

2) Precipitation and deposition method (PD): A $\mathrm{H}_{2} \mathrm{PdCl}_{4}$ solution was prepared by dissolving $0.833 \mathrm{~g} \mathrm{PdCl}$ in $85 \mathrm{~mL}$ of $0.067 \mathrm{M} \mathrm{HCl}$ in a flask $(500 \mathrm{~mL})$ while stirring at $1.500 \mathrm{rpm}$ for 30 minutes. An activated carbon solution was prepared by introducing $9.5 \mathrm{~g}$ of activated carbon into $120 \mathrm{~mL}$ of $1 \mathrm{M} \mathrm{Na}_{2} \mathrm{CO}_{2}$ and stirring at $60^{\circ} \mathrm{C}$ for 40 minutes in a flask $(500 \mathrm{~mL})$. Eighty-five $\mathrm{mL}$ of the $\mathrm{H}_{2} \mathrm{PdCl}_{4}$ solution was then transferred into the activated carbon solution at a flow rate of $3 \mathrm{~mL} / \mathrm{min}$ and maintained for 60 minutes while stirring vigorously $(\mathrm{pH}=11)$. The catalyst prepared by $\mathrm{PD}$ was filtered by flushing with hot deionised water and dried 
$\left(50{ }^{\circ} \mathrm{C}, 12\right.$ hours). reduced $\left(100{ }^{\circ} \mathrm{C} .50 \mathrm{~mL} / \mathrm{min} \mathrm{H}_{-}\right)$. and stored in a desiccator $(10 \mathrm{~g} \mathrm{Pd} / \mathrm{C})$. During catalyst preparation by $\mathrm{PD}$. the precipitation temperature, $\mathrm{pH}$ of precipitation solution. dropping rate of $\mathrm{H}_{2} \mathrm{PdCl}_{4}$ solution. and reducing agent were changed as follows.

A. Variation of precipitation temperature

After adsorbing aqueous $1 \mathrm{M} \mathrm{Na}_{2} \mathrm{CO}_{3}$ into activated carbon, the temperature of this carbon solution was varied into the four cases of $25^{\circ} \mathrm{C} .40^{\circ} \mathrm{C} .60^{\circ} \mathrm{C}$ and $80^{\circ} \mathrm{C}$.

B. Variation of dropping rate of $\mathrm{H}_{2} \mathrm{PdCl}_{4}$ solution

At a given precipitation temperature condition of $60^{\circ} \mathrm{C}$. the three dropping rates of the $\mathrm{H}_{2} \mathrm{PdCl}_{4}$ solution used were $\mathrm{I}$ $\mathrm{mL} / \mathrm{min}, 2 \mathrm{~mL} / \mathrm{min}$, and $3 \mathrm{~mL} / \mathrm{min}$.

$\mathrm{C}$. Variation of reducing agent

The prepared $\mathrm{Pd} / \mathrm{C}$ catalysts were reduced using three different methods. Two of these involved reduction in the liquid phase by $\mathrm{HCHO}$ or $\mathrm{NaBH}_{4}$. After precipitation, the catalyst reduction with $\mathrm{HCHO}$ was carried out at $80^{\circ} \mathrm{C}$ by introducing $3.5 \mathrm{~mL}$ of $36 \% \mathrm{HCHO}$ and stirring for 1.5 hours. The reduced catalyst was filtered with $2 \mathrm{~L}$ of hot dejonised water and stored in a desiccator in the wet state. The catalyst reduction with $\mathrm{NaBH}_{4}$ was performed at room temperature by introducing the $1.238 \mathrm{~g}$ of $\mathrm{NaBH}_{4}$ and stirring for 2 hours. The catalyst was filtered and stored under the same treatment condition of $\mathrm{Pd} / \mathrm{C}$ reduced with HCHO. The catalyst reduction in the vapor phase was performed at $100^{\circ} \mathrm{C}$ for 2 hours with $50 \mathrm{~mL} / \mathrm{min}$ of $\mathrm{H}_{2}(\mathrm{~g})$.

Characterization. The supports and catalysts were characterized by pore volume, Langunuir surface area. BJH pore size distribution, and HK micro pore size distribution measurements (Quitachrom AUTOSORB-1-C), and by transmission electron microscope (TEM) (JEM-3010).

Reaction apparatus and procedures. The BP hydrogenation reaction was carried out using a $200 \mathrm{~mL}$ Büchi autoclave as shown in Figure 1.

The reaction temperature was controlled by circulating a heating medium through the reactor jacket. The holes running top-to-bottom in the center of the shaft and at the side of the impeller helped to introduce $\mathrm{H}_{2}$ gas into the reaction media. A dip tube with two ball valves installed on the sampling line outside of the reactor was inserted inside the reactor to extract product samples. Dry catalyst $(0.0125 \mathrm{~g}$
Pd) in a small amount of solvent was transferred into the reactor. and reactant diluted with $1,100 \mathrm{~mL}$ IPA was added afterwards. The reactor was purged with nitrogen gas and hydrogen gas, sequentially. The reaction was performed at $165^{\circ} \mathrm{C} .8$ bar. and $1.000 \mathrm{rpm}$ of agitation speed. The reaction samples taken regularly were filtered to remove catalyst. diluted with IPA. and analyzed by a gas chromatograph (Hewlett-Packard $6890^{+}$using a HP-5 $5 \%$ phenyl methyl siloxane capillary column $(30 \mathrm{~m} \times 320 \mu \mathrm{m} \times 0.25 \mu \mathrm{m}))$. Identification of the product was done using mass fragmentation from the GC-MS (Fisons MD800).

\section{Results and Discussion}

Differences in the reaction selectivity among differently prepared catalysts. The characteristics of hydrogenation of biphenol (BP) over various $\mathrm{Pd} / \mathrm{C}$ catalysts were examined. The reaction scheme of BP hydrogenation was reported in the previous work with the reaction pathways shown in the Figure 2.4 As BP was hydrogenated with $\mathrm{Pd} / \mathrm{C}$, 4-(4-hydroxy-cyclohexyl)-cyclohexanone (HPCN). bicyclohexyl-4.4'-

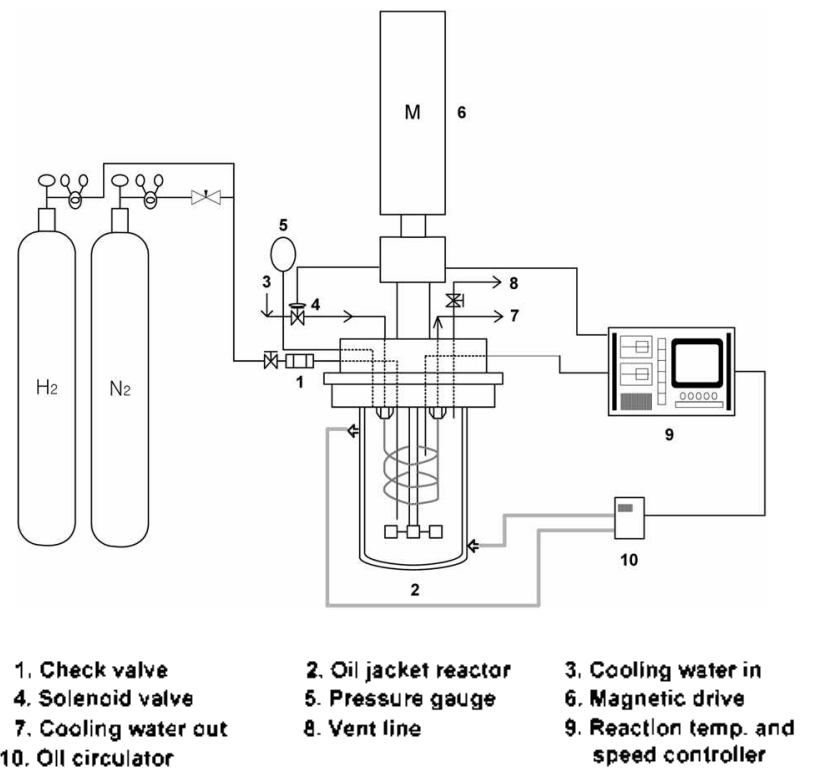

Figure 1. Apparatus for the BP hydrogenation reaction.

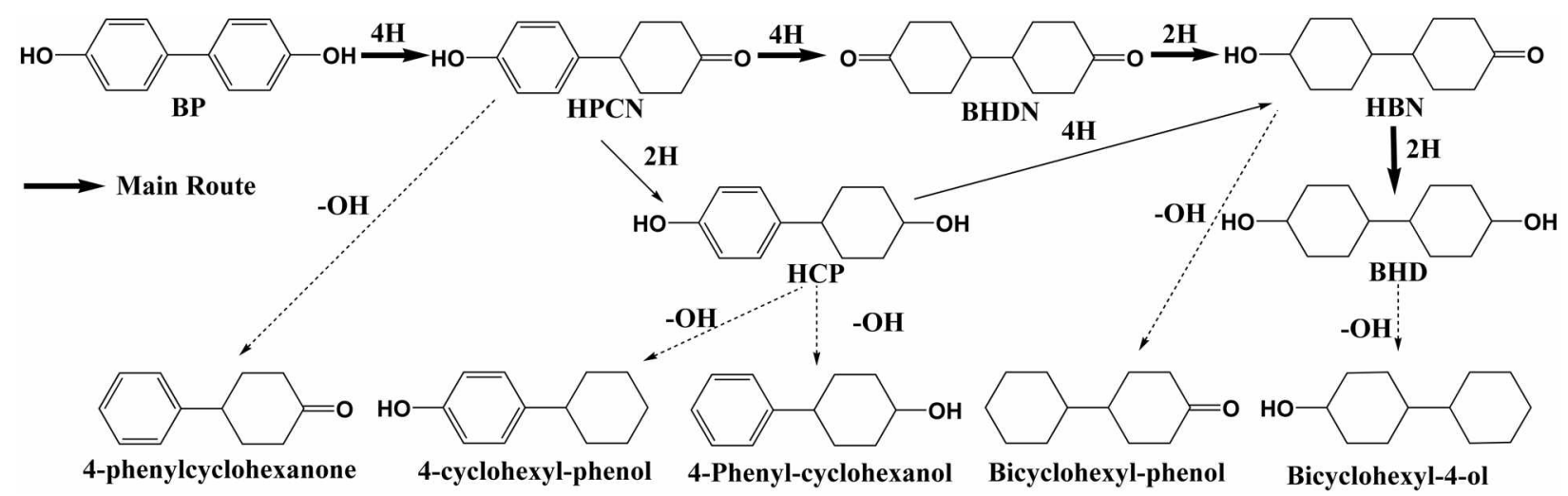

Figure 2. The reaction scheme of $\mathrm{BP}$ hydrogenation over $\mathrm{Pd} / \mathrm{C}$ (Kawaken ). ${ }^{4}$ 

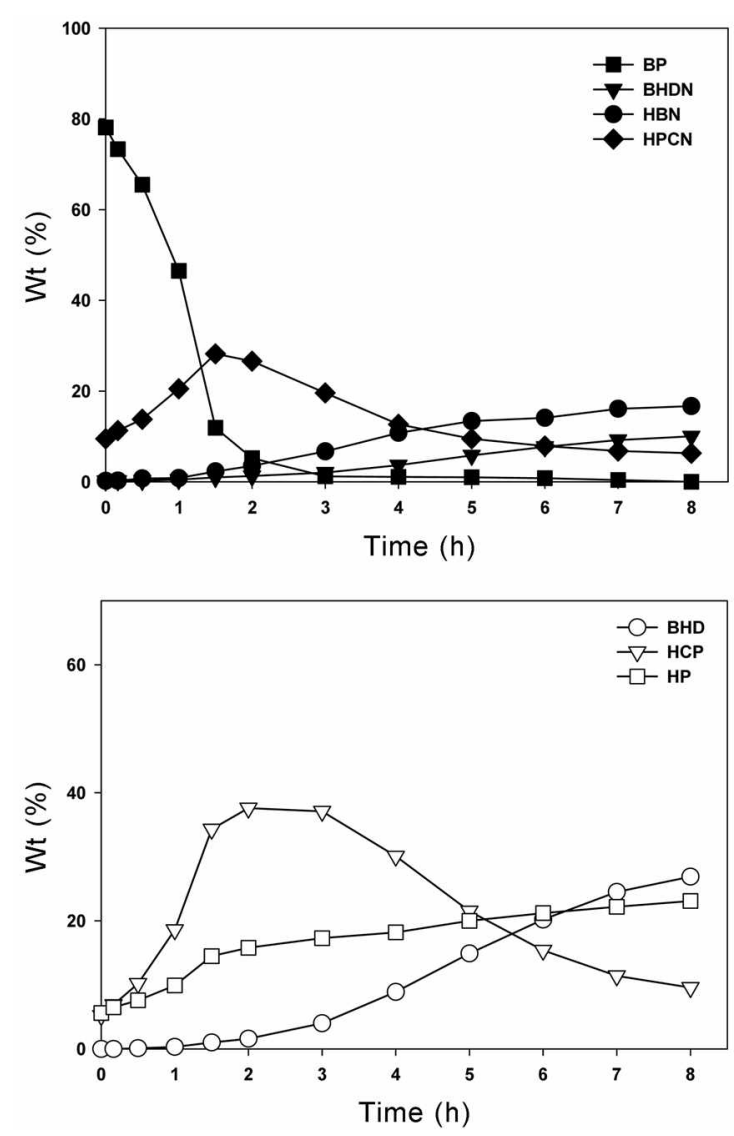

Figure 3. The product concentrations in reaction misture according to the reaction time over $\mathrm{Pd} / \mathrm{C}$ (IW): (HP: hydrogenolysis product) (temperature $165^{\circ} \mathrm{C}$, pressure 8 bar, agitation speed 1,000 rom, catalyst loading $0.0125 \mathrm{~g} \mathrm{Pd} / \mathrm{BP} 5 \mathrm{~g}$ ).

dione (BHDN). 4-4-(hydroxyl-cyclohexyl)-phenol (HCP) and 4 -hydroxy-bicyclohexyl-t-one (HBN) were obtained as internediate products. while bicyclohexyl-4.t'-diol (BHD) was produced as a fully saturated one. The hydrogenolysis products (designated as HP) were believed to be obtained in each step of BP hydrogenation.

The product concentrations in reaction mixture according to the reaction time over different $\mathrm{Pd} / \mathrm{C}$ catalysts are shown in Figure 3-5. With $\mathrm{Pd} / \mathrm{C}$ (IW) (Figure 3). all of $\mathrm{BP}$ was converted in two hours. HPCN and HCP formed and disappeared slowly. Hydrogenolysis products increased steadily from the beginning. while HBN and BHD increased after HCP reaching the maximum concentration. With prepared $\mathrm{Pd} / \mathrm{C}$ (PD) (Figure 4). the formation of HP was much less than in the case of $\mathrm{Pd} / \mathrm{C}$ (IW). while other profiles showed a similar trend with $\mathrm{Pd} / \mathrm{C}$ (IW). With $\mathrm{Pd} / \mathrm{C}$ (Kawaken) (Figure 5), the entire amount of BP was converted within 1 hour. which facilitated the formation and consumption of $\mathrm{HPCN}$ to produce either BHDN ( $80 \%$ in 2 hours) or HCP ( $2 \%$ in 1 hour). However. the hydrogenation of BHDN was not completed until 8 hours of reaction and the yield of BHD was much lower than those from $\mathrm{Pd} / \mathrm{C}$ (IW) or $\mathrm{Pd} / \mathrm{C}$ (PD).

The catalytic performances of these catalysts are summarized in Table 1. The initial conversions of BP with the prepared catalysts were much lower than that with $\mathrm{Pd} / \mathrm{C}$
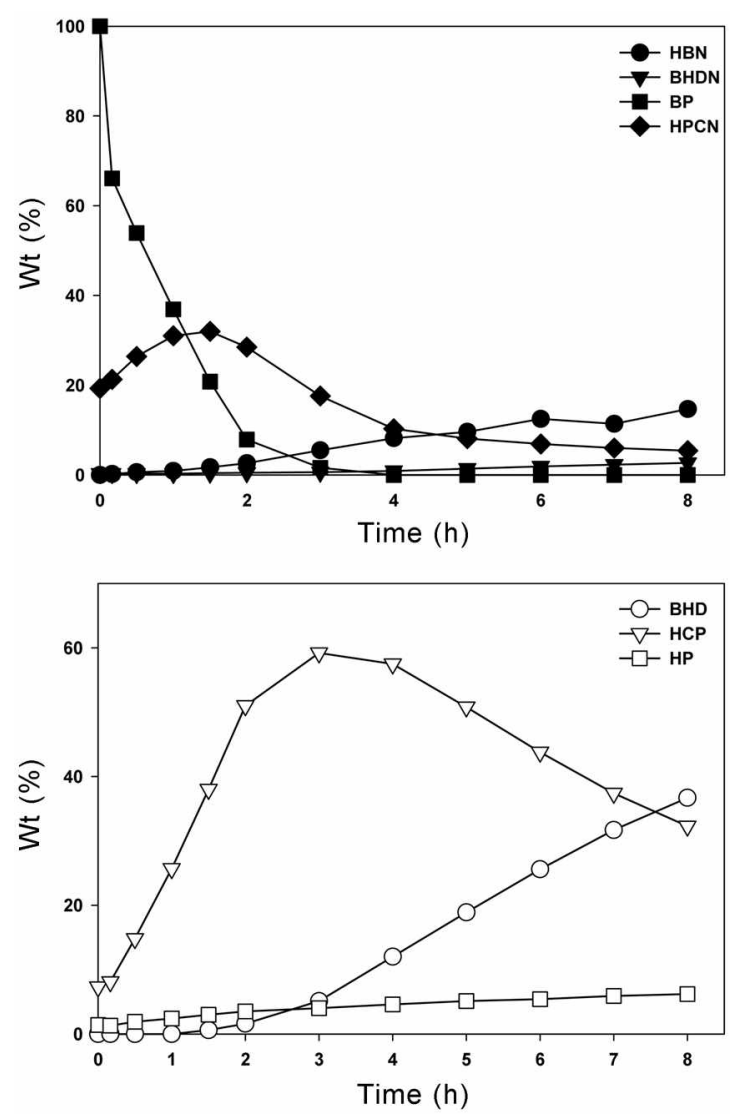

Figure 4 . The product concentrations in reaction mixture according to the reaction time over $\mathrm{Pd} / \mathrm{C}$ ( $\mathrm{PD}$ ): (HP: hydrogenolysis product) (temperature 165 " $\mathrm{C}$, pressure $8 \mathrm{bar}$, agitation speed $1,000 \mathrm{rpm}$, catalyst loading $0.0125 \mathrm{~g} \mathrm{Pd} / \mathrm{BP} 5 \mathrm{~g}$ ).

(Kawaken). However. the yield to BHD with a prepared Pd/ $\mathrm{C}$ (PD) catalyst was the highest $(36.7 \%)$, which was more than 7 times higher than that with $\mathrm{Pd} / \mathrm{C}$ (Kawaken) $(4.9 \%)$. The $\mathrm{Pd} / \mathrm{C}$ (IW) also showed a much higher yield to BHD than did the commercial catalyst. but its selectivity was lowered due to an increase of the hydrogenolysis products (HP).

In order to understand the reason for the differences in the initial BP conversion and BHD selectivity of three catalysts. the distribution of active metal particles. pore structure of each catalyst. and diffusion limitation of substrates and intermediates were examined. The physical properties of the prepared catalysts are shown in Table 2 . The surface areas of the catalysts are in the range of $1000-2400 \mathrm{~m}^{2} / \mathrm{g}$ and those of the prepared catalysts were much lower than $\mathrm{Pd} / \mathrm{C}$ (Kawaken). The micro pore size distribution measured by HK method (Figure 6) shows that the micro pores of the prepared catalysts are less developed than those of the commercial catalyst. $\mathrm{Pd} / \mathrm{C}$ (Kawaken). On the other hand. the Pd loadings of the three catalysts were found to be similar.

The shapes of metal particles were studied with TEM (Figure 7). $\mathrm{Pd} / \mathrm{C}$ (PD) has large metal particles of sizes up to $10 \mathrm{~nm} . \mathrm{Pd} / \mathrm{C}$ (Kawaken) has metal particles smaller than 5 $\mathrm{nm}$, and $\mathrm{Pd} / \mathrm{C}$ (IW) has much smaller metal particles. Since all three catalysts have similar metal loading. the number of 

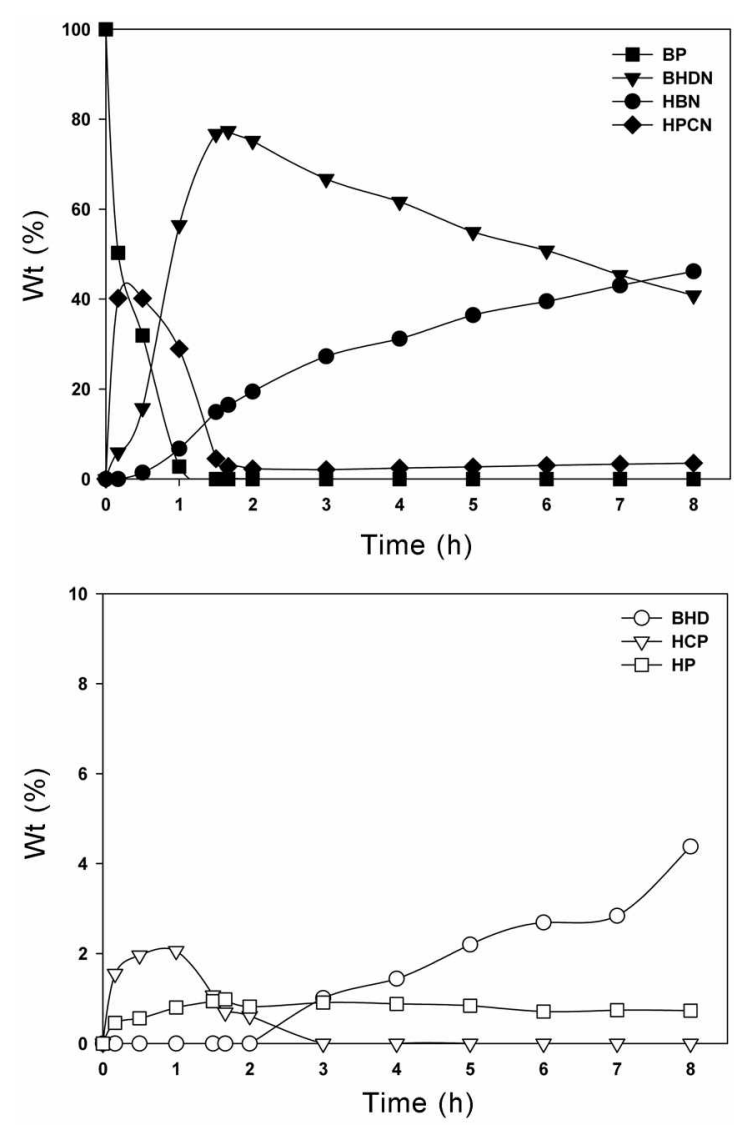

Figure 5. The product concentrations in reaction misture according to the reaction time over $\mathrm{Pd} / \mathrm{C}$ (Kawaken), a commercial catalyst (HP: hydrogenolysis product) (temperature $165^{\circ} \mathrm{C}$, pressure 8 bar, agitation speed $1,000 \mathrm{rpm}$, catalyst loading $0.0125 \mathrm{~g} \mathrm{Pd} / \mathrm{BP} 5 \mathrm{~g})^{+}$

Table 1. Catalytic perfornance of various $\mathrm{Pd} / \mathrm{C}$ catalysts

\begin{tabular}{|c|c|c|c|}
\hline \multirow{2}{*}{$\begin{array}{l}\text { Type of } \mathrm{Pd} / \mathrm{C} \\
\text { preparation }\end{array}$} & \multirow{2}{*}{$\begin{array}{c}\text { Initial rate } \\
\left(\text { (numol g-cat }{ }^{-1} \cdot \mathrm{min}^{-1}\right)\end{array}$} & \multicolumn{2}{|c|}{ Yield $(\%)$} \\
\hline & & $\mathrm{BHD}$ & $\mathrm{HP}$ \\
\hline $\mathrm{Pd} / \mathrm{C}(\mathrm{IW})^{\sigma}$ & 19.07 & 27.0 & 23.1 \\
\hline $\mathrm{Pd} / \mathrm{C}(\mathrm{PD})^{b}$ & 22.49 & 36.7 & 6.2 \\
\hline $\mathrm{Pd} / \mathrm{C}$ (Kawaken $)^{c}$ & 34.67 & 4.9 & 0.7 \\
\hline
\end{tabular}

"PdC prepared by incipient wetness method: reduction for $2 \mathrm{~h}, 50 \mathrm{~mL}$. min $\mathrm{H}_{2}$ at $100{ }^{\circ} \mathrm{C}$. $\mathrm{Pd} \mathrm{C}$ prepared by precipitation and deposition method: precipitation at $60^{\circ} \mathrm{C}$. reduction for $2 \mathrm{~h}, 50 \mathrm{~mL}$ min $\mathrm{H}_{2}$ at 100 ${ }^{\circ} \mathrm{C} .{ }^{c}$ Commercial Pd C from Kawaken Fine Chemical Co.

$\mathrm{Pd} / \mathrm{C}$ (PD) metal particles should be smaller than other catalysts. It is known ${ }^{5.7}$ that with precipitation and deposition method $(\mathrm{PD})$, precipitates formed in the bulk solution

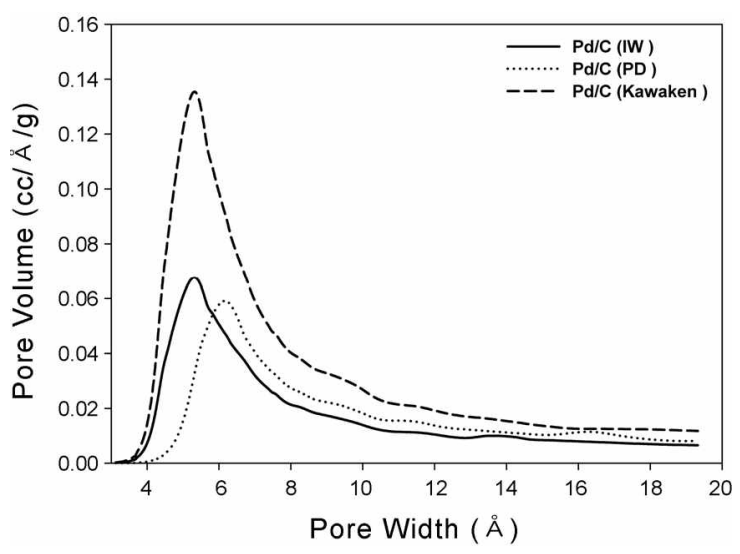

Figure 6. HK micro pore size distribution of $\mathrm{Pd} / \mathrm{C}$ catalysts.

and need to diffuse into the pore of carbon so that particles are mainly located on the outer surface of carbon particles. Catalysts prepared from incipient wetness are usually known to have small particle size throughout the whole support surface due to quick adsorption of precursors by capillary force. ${ }^{8}$ Therefore, it is expected that an eggshell-type metal distribution was formed on $\mathrm{Pd} / \mathrm{C}$ (PD) and a uniform metal distribution was formed on $\mathrm{Pd} / \mathrm{C}$ (IW). The metal distribution in $\mathrm{Pd} / \mathrm{C}$ (Kawaken) seems to be in the intermediate range.

The pore structures of the catalysts were different from each other according to Table 2; $\mathrm{Pd} / \mathrm{C}$ (PD) and $\mathrm{Pd} / \mathrm{C}$ (IW) have larger pore diameter and lower percentage of micro pore than $\mathrm{Pd} / \mathrm{C}$ (Kawaken). So the diffusion of bulky reactants within the pore of the catalysts can play important roles in giving for the different conversions of BP and selectivity of BHD. It is regarded that the difference of diffusional limitation of the reactant molecules between $\mathrm{BP}$ and $\mathrm{HBN}$ in solvent are significant, as illustrated in Figure 8. According to the kinetic diameters of molecules undergoing diffusion in porous media, ${ }^{y} \mathrm{BP}$ or HBN molecules can be estimated to range from 1.2-1.6 $\mathrm{nm}$. When two types of molecules are adsorbed on the catalyst metal inside the carbon. BP with flat molecular structure can reach the deeper micropores of the carbon than HBN with a bulky structure. Even when HBN molecule manages to reach the surface of the metal site inside the micropore. it still has difficulties in adsorbing on the catalyst metal surface due to its bulky structure since the $\mathrm{C}=\mathrm{O}$ bond of $\mathrm{HBN}$ has to be located on the surface of the metal horizontally with other parts in a slant-like orientation (Figure 8(a)). So BP can be well converted to HPCN during the initial step of hy'drogenation over Pd metal located on the

Table 2. Surface properties of $\mathrm{Pd} / \mathrm{C}$ catalysts

\begin{tabular}{lccccc}
\hline Catalyst & $\begin{array}{c}\text { Surface area } \\
(\mathrm{m} / \mathrm{g})\end{array}$ & $\begin{array}{c}\text { Micro pore } \\
\text { volume }(\mathrm{cc} / \mathrm{g})\end{array}$ & $\begin{array}{c}\text { Maximum pore } \\
\text { diameter }\end{array}$ & $\begin{array}{c}\text { Ratio of micro } \\
\text { pore/total pore }(\mathrm{Ac} / \mathrm{min})\end{array}$ & $\begin{array}{c}\text { Pd } \\
(\mathrm{wt} \%)\end{array}$ \\
\hline Pd/C (IW) & 1,092 & 0.96 & 38.56 & 0.31 & 3.46 \\
Pd/C (PD) & 1,615 & 1.15 & 39.08 & 0.39 & 3.68 \\
Pd/C (Kawaken) & 2,391 & 1.36 & 36.07 & 0.47 & 3.62 \\
\hline
\end{tabular}

"surface area was determined based on the Langmuir isotherm. "mavimum pore diameter was detenmined based on BJH pore size distribution. "amount of Pd loading according to ICP analy sis. 


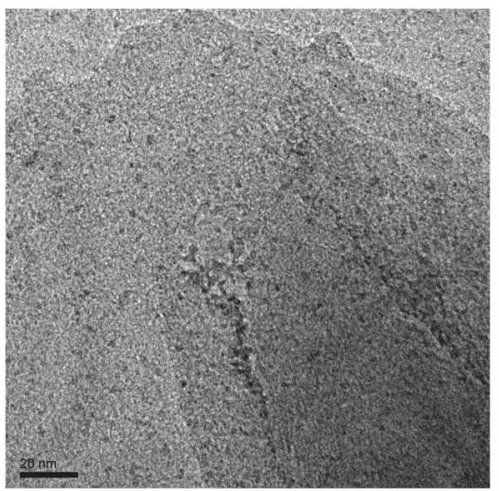

(a)

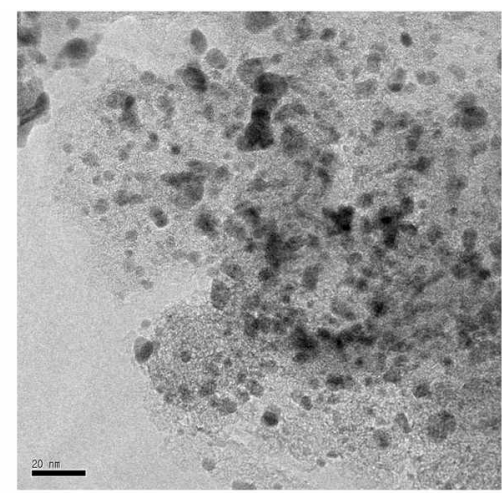

(b)

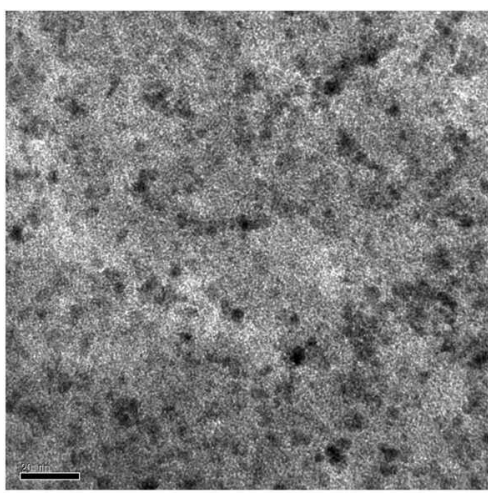

(c)

Figure 7. TEM image of catalysts: a) $\mathrm{Pd} / \mathrm{C}$ (IW), b) $\mathrm{Pd} / \mathrm{C}$ (PD), and c) $\mathrm{Pd} / \mathrm{C}$ (Kawaken). Scale bar corresponds to $20 \mathrm{~nm}$.

(a)

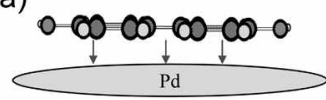

Adsorption of two benzene rings of BP on Pd metal (view from the side)

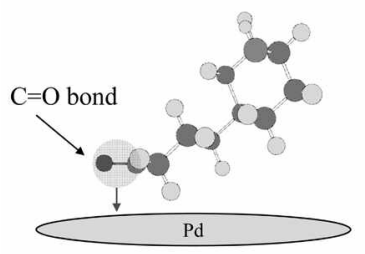

Adsorption of $\mathrm{C}=\mathrm{O}$ bond of $\mathrm{HBN}$ on Pd metal

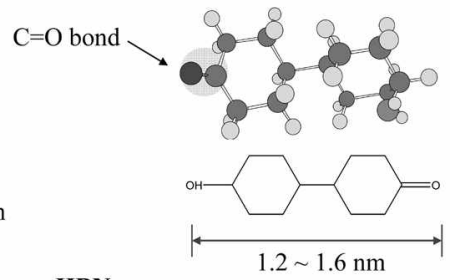

HBN

(b)

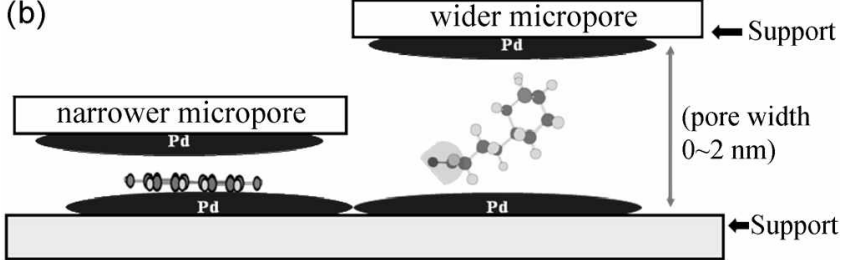

HBN with bulky structure can penetrate only to outer micropore while BP with flat structure can reach Pd located in deeper micropore

Figure 8. Diffusional limitation of $\mathrm{BP}$ and $\mathrm{HBN}$ molecules in the pore of $\mathrm{Pd} / \mathrm{C}$ catalysts.

deeper micropores, while $\mathrm{HBN}$ will face difficulty in being further hydrogenated to BHD. On the contrary. HBN will not face such difficulty if $\mathrm{Pd}$ particles located on the outer surface of carbon. Therefore. it is believed that HBN can produce BHD in hydrogenation easily with $\mathrm{Pd} / \mathrm{C}$ (PD) which has active metal on the outer shell of the carbon while mass transfer and reaction of $\mathrm{HBN}$ was hindered on $\mathrm{Pd} / \mathrm{C}$ (Kawaken) to low yield of BHD. The reports that the diffusion of reactant molecules into microporous media were more highly affected by steric hindrance especially in the liquid phase reaction. ${ }^{15.12}$ support that the product selectivity in BP hydrogenation is dependent on the pore structure and the distribution of catalyst metal particles.
It was notable that reaction with $\mathrm{Pd} / \mathrm{C}$ (IW) produced higher amount of HP than $\mathrm{Pd} / \mathrm{C}$ (PD). This seems to be related to differences in the preparation procedure of $\mathrm{Pd} / \mathrm{C}$. Since $\mathrm{Pd} / \mathrm{C}$ (IW) was prepared under acidic conditions (as described in experimental section) and was not washed afterwards. the catalyst inevitably has acid left on the support, which is not the case with the $\mathrm{Pd} / \mathrm{C}$ (PD). The acid site on the support seems to invoke hydrogenolysis. It was reported that hydrogenolysis product was enhanced in the hydrogenolysis of aromatic phenol by the presence of acids in polar solvents. ${ }^{13}$

Effect of preparation parameters of $\mathrm{Pd} / \mathrm{C}$ prepared from precipitation and deposition method, $\mathrm{Pd} / \mathrm{C}(\mathrm{PD})$, on the BP hydrogenation. In BP hydrogenation perfomed with different $\mathrm{Pd} / \mathrm{C}$ catalysts. the catalyst prepared by precipitation and deposition (PD) exhibited the best perfor-

Table 3. Effect of the preparation parameters of Pd/C (PD method)

\begin{tabular}{|c|c|c|c|c|}
\hline \multirow{2}{*}{$\begin{array}{l}\text { Preparation } \\
\text { parameters }\end{array}$} & \multirow{2}{*}{ Variation } & \multirow{2}{*}{ 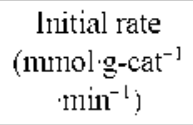 } & \multicolumn{2}{|c|}{ Yield (\%) } \\
\hline & & & $\mathrm{BHD}$ & $\mathrm{HP}$ \\
\hline \multirow{4}{*}{$\begin{array}{l}\text { Precipitation } \\
\text { temperature } \\
\left({ }^{\circ} \mathrm{C}\right)\end{array}$} & $25^{\circ} \mathrm{C}$ & 30.69 & 16.3 & 12.1 \\
\hline & $40^{\circ} \mathrm{C}$ & 33.68 & 14.0 & 14.0 \\
\hline & $60^{\circ} \mathrm{C}$ & 22.49 & 36.7 & 6.2 \\
\hline & $80^{\circ} \mathrm{C}$ & 34.46 & 13.6 & 140 \\
\hline \multirow{4}{*}{$\mathrm{pH}$} & $6^{c}$ & 4.03 & 1.3 & 4.3 \\
\hline & $9^{c}$ & 20.85 & 17.1 & 17.8 \\
\hline & $11^{\circ}$ & 24.27 & $\mathrm{l} 0.9$ & 42.4 \\
\hline & $11^{d t}$ & 22.49 & 36.7 & 6.2 \\
\hline \multirow{3}{*}{$\begin{array}{l}\text { Precursor } \\
\text { dropping rate } \\
\text { (mL/min) }\end{array}$} & 1 & 13.61 & 5.8 & 15.4 \\
\hline & 2 & 33.64 & 26.7 & 6.0 \\
\hline & 3 & 22.49 & 36.7 & 6.2 \\
\hline \multirow{3}{*}{ Reducing agent } & $\mathrm{HCHO}$ & 35.64 & 11.7 & 22.5 \\
\hline & $\mathrm{NaBH}_{4}$ & 33.47 & 12.2 & 15.4 \\
\hline & $\mathrm{H}_{2}$ & 22.49 & 36.7 & 6.2 \\
\hline
\end{tabular}

"Catalyst reduction: 2 h. $50 \mathrm{~mL}$ min $\mathrm{H}_{2}$ at $100 \% \mathrm{C}$. "Precipitation (basis): flow rate of $\mathrm{H}_{2} \mathrm{PdCl}_{4} 3 \mathrm{~mL}$ min. $60 \% \mathrm{C}$; reduction: $2 \mathrm{~h}, 50 \mathrm{~mL}$ min $\mathrm{H}_{2}$. $100{ }^{\circ} \mathrm{C}$. 'Precursor solution. $\mathrm{H}_{2} \mathrm{PdCl}_{4}$. was introduced to carbon suspended in $0.03 \mathrm{M} \mathrm{Na}_{2} \mathrm{CO}_{3}$ solution. and $\mathrm{Na}_{2} \mathrm{CO}_{3}$ was added until the desired $\mathrm{pH}$ value $(\mathrm{pH}=6-11)$ was obtained. "Precursor solution. $\mathrm{H}_{2} \mathrm{PdCl}_{4}$, was introduced to carbon suspended in $1.0 \mathrm{M} \mathrm{Na}_{2} \mathrm{CO}_{3}(\mathrm{pH}=11)$. 


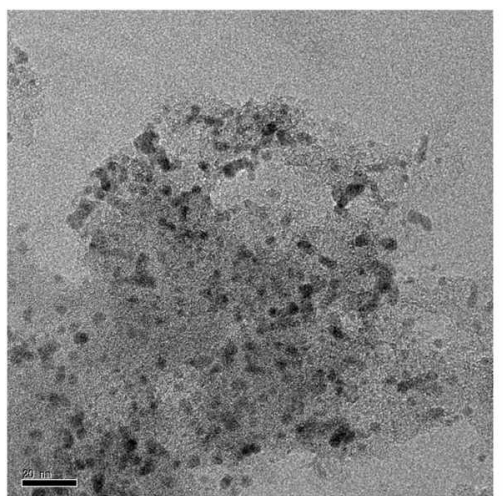

(a)

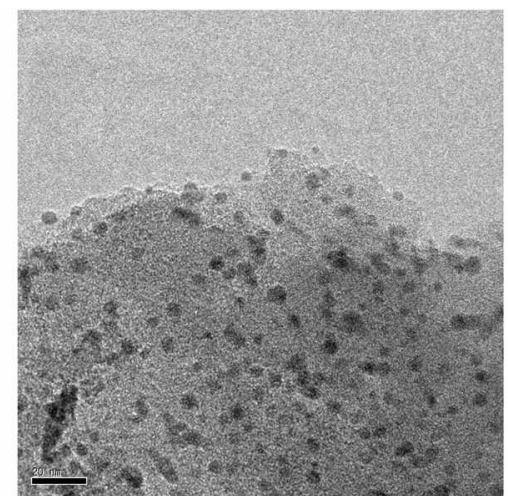

(b)

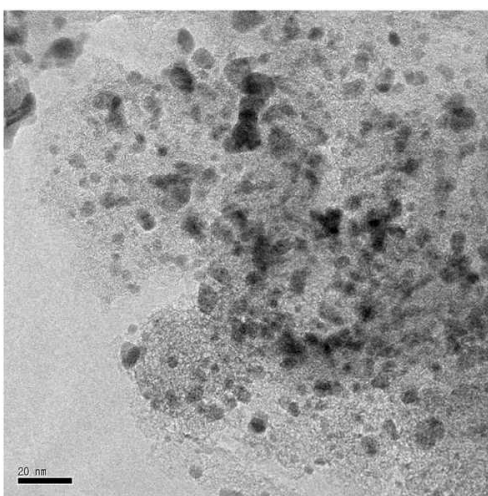

(c)

Figure 9. TEM image of catalysts: (a) $\mathrm{Pd} / \mathrm{C}(\mathrm{HCHO})$, (b) $\mathrm{Pd} / \mathrm{C}\left(\mathrm{NaBH}_{4}\right)$, and (c) $\mathrm{Pd} / \mathrm{C}\left(\mathrm{H}_{2}\right)$. Scale bar corresponds to $20 \mathrm{~nm}$.

mance in producing BHD. Therefore, studies were done to find the effects of the preparation parameters during precipitation and deposition. The results of changes of preparation parameters of $\mathrm{Pd} / \mathrm{C}(\mathrm{PD})$ are described in Table 3 .

When the precipitation temperature was increased. the initial conversion of BP increased at temperatures up to 40 ${ }^{\circ} \mathrm{C}$. decreased to its minimum at $60{ }^{\circ} \mathrm{C}$ and then increased at $80^{\circ} \mathrm{C}$. Even though the catalyst precipitated at $60^{\circ} \mathrm{C}$ converted $\mathrm{BP}$ the most slowly, it produced the highest amount $(36.7 \%)$ of BHD, which was over twice the amount produced by the other catalysts. In addition, the amount of HP was less than half of the anounts produced with the other cataly sts.

When the $\mathrm{pH}$ of precipitation solution was varied, the initial rate of $\mathrm{BP}$ conversion changed significantly. With the cataly st precipitated at a weak acidic solution $(\mathrm{pH} 6)$, the rate of BP conversion was very low (4.03 mmolg- $\mathrm{cat}^{-1} \mathrm{~min}^{-1}$ ). When the $\mathrm{pH}$ was increased to 11. the rate of $\mathrm{BP}$ conversion increased more than 5 times.

Changing the concentration of $\mathrm{Na}_{2} \mathrm{CO}_{3}$ solution also affected catalytic activity. The catalyst prepared with a lower concentration of alkali $\left(0.03 \mathrm{M} \mathrm{Na}_{2} \mathrm{CO}_{3}\right)$ exhibited higher catalytic activity at initial reaction period than that prepared with a higher concentration of alkali $\left(1.0 \mathrm{M} \mathrm{Na}_{2} \mathrm{CO}_{3}\right)$. On the contrary a much higher yield to BHD $(36.7 \%)$ was obtained from the catalyst prepared with the $1.0 \mathrm{M} \mathrm{Na}_{2} \mathrm{CO}_{3}$ concentration than that prepared with the lower concentration of alkali.

Variation of the precursor dropping rate also resulted in different catalytic performances in the reaction. The initial $\mathrm{BP}$ conversion was highest when the catalyst was prepared with a dropping rate of $2 \mathrm{~mL} / \mathrm{min}(\mathrm{Pd} / \mathrm{C}(2 \mathrm{~mL} / \mathrm{min}))$. $\mathrm{Pd} / \mathrm{C}$ with a dropping rate of $3 \mathrm{~mL} / \mathrm{min}$ exhibited a lower $\mathrm{BP}$ conversion than $\mathrm{Pd} / \mathrm{C}(2 \mathrm{~mL} / \mathrm{min})$ but gave the highest yield of BHD and the lower amount of hydrogenolysis product (HP) $(6.2 \%)$.

The variation in the type of the reducing agent also affected catalytic activity greatly. The initial rate with $\mathrm{Pd} / \mathrm{C}$ catalysts reduced in the liquid phase was higher than the one reduced by $\mathrm{H}_{\Sigma}(\mathrm{g})\left(\mathrm{Pd} / \mathrm{C}\left(\mathrm{H}_{2}\right)\right)$. Among these. $\mathrm{Pd} / \mathrm{C}$ reduced with $\mathrm{HCHO}, \mathrm{Pd} / \mathrm{C}(\mathrm{HCHO})$. showed the highest activity
(33.47 mmol g-cat $\left.{ }^{-1} \mathrm{~min}^{-1}\right) . \mathrm{Pd} / \mathrm{C}$ reduced in the gas phase converted BP the most slowly in the initial stage of reaction (22.49 mmol $\mathrm{g}^{-\mathrm{cat}^{-1}} \mathrm{~mm}^{-1}$ ), but this catalyst gave much higher amount of BHD than other catalysts.

The reaction experiments with catalysts prepared at various temperature showed that $60^{\circ} \mathrm{C}$ is the best preparation temperature in producing $\mathrm{BHD}$ while the catalyst prepared at $80^{\circ} \mathrm{C}$ gave the fastest conversion of BP. It was reported that nuclei formation is slow at low temperatures during precipitation of palladium. ${ }^{5}$ At $25^{\circ} \mathrm{C}$ particles may not be formed enough in the given precipitation time due to low rate of nuclei formation. It is also known that the solubility of metal precursor is increased at higher temperature. ${ }^{5}$ so the rate of nucleation would be also low due to low degree of supersaturation at $80^{\circ} \mathrm{C}$ to give small metal particles. It seems that larger particles of the insoluble $\mathrm{Pd}(\mathrm{OH})_{2}$ crystals are formed during precipitation $60^{\circ} \mathrm{C}$ to deposit more metal on the outer shell of support, giving a high yield of BHD by the reason explained above.

Regarding to the effect of $\mathrm{pH}$ during catalyst precipitation, the yield of $\mathrm{BHD}$ was increased at higher $\mathrm{pH}(\mathrm{pH}=11)$ and with a faster precursor dropping rate $(3 \mathrm{~mL} / \mathrm{min})$. It is known that as $\mathrm{pH}$ increases. the rate of precursor lydrolysis increases. which means that the formation of precipitates becomes faster in the bulk solution at higher $\mathrm{pH}$ conditions. ${ }^{6}$ In addition. during catalyst preparation from precipitation and deposition. the precipitates are formed in the bulk solution and experience diffusion resistance during their particle deposition on the surface of carbon. ${ }^{5}$ Therefore. the more precipitates are fonmed in the solution outside of carbon, the more crystals are located on the outer surface of the support. In addition. a high dropping rate of precursor preparation causes a high concentration of metal precursor to invoke formation of more precipitates in the solution and preferred metal deposition in the outer shell of the catalyst. It is thought that a higher $\mathrm{pH}$ and faster dropping rate lead to metal deposition on the outer shell. facilitating the higher yield and selectivity to BHD

Though the catalysts reduced in the liquid phase enhanced the initial $\mathrm{BP}$ conversion. the one reduced in the gas phase increased the selectivity to BHD. The observation that the 
$\mathrm{Pd} / \mathrm{C}\left(\mathrm{H}_{2}\right)$ has larger metal particles than $\mathrm{Pd} / \mathrm{C}(\mathrm{HCHO})$ or $\mathrm{Pd} / \mathrm{C}(\mathrm{NaBH})$ indicates that the $\mathrm{Pd} / \mathrm{C}$ catalysts reduced in the liquid phase have smaller particle sizes than the one reduced in the gas phase (Figure 9). It seens that metal migration and sintering occurred on the carbon surface during $\mathrm{H}_{2}$ reduction at $100{ }^{\circ} \mathrm{C}$ while reduction in the liquid phase is less susceptible to sintering due to its milder reduction conditions (see Experimental Section). With $\mathrm{H}_{2}$ reduction. the larger metal crystals seem to be formed mainly on the outer shell of support giving a higher BHD yield.

Changes in the reaction mechanism with catalyst preparation methods. It was observed in the BP hydrogenation over three catalysts (Figure 3-5) that different ratio of intermediate products were obtained from hydrogenation of HPCN ( $1^{\text {st }}$ intermediate product from BP hydrogenation) depending on the catalyst used. With $\mathrm{Pd} / \mathrm{C}$ (IW), the consumed HPCN was converted to HCP rather than BHDN through hydrogenation of the ketone group of $\mathrm{HPCN}(\mathrm{C}=\mathrm{O}$ bond hydrogenation). This tendency was more obvious with $\mathrm{Pd} / \mathrm{C}$ (PD) because the yield of HCP from 3 hour reaction was $60 \%$ while that of $\mathrm{BHDN}$ was less than $5 \%$. However. with $\mathrm{Pd} / \mathrm{C}$ (Kawaken), the consumed HPCN was converted mainly to BHDN ( $80 \%$ yield in 2 hour reaction) through hydrogenation of benzene group $(\mathrm{C}=\mathrm{C}$ bond hydrogenation). This observation that $\mathrm{C}=\mathrm{O}$ bond hydrogenation was preferable with $\mathrm{Pd} / \mathrm{C}(\mathrm{IW})$ and $\mathrm{Pd} / \mathrm{C}(\mathrm{PD})$ while $\mathrm{C}=\mathrm{C}$ bond hydrogenation was preferable with $\mathrm{Pd} / \mathrm{C}$ (Kawaken) indicate that the reaction route of $\mathrm{BP}$ hydrogenation is different depending on the type of catalyst. It is worthwhile to understand how such a change in the reaction mechanism can occur in the cataly tic hydrogenation of BP.

It is known that $\mathrm{C}=\mathrm{C}$ bond hydrogenation is preferred to $\mathrm{C}=\mathrm{O}$ bond hydrogenation from thermodynamic standpoint when these two bond exist in the substrate molecule. ${ }^{14}$ Due to the higher stability of the $\mathrm{C}=\mathrm{O}$ bond. $\mathrm{C}=\mathrm{C}$ bond hydrogenation needs about $35 \mathrm{~kJ} / \mathrm{mol}$ less energy than $\mathrm{C}=\mathrm{O}$ bond hydrogenation. Therefore. it is not easy to expect that the $\mathrm{C}=\mathrm{O}$ bond of $\mathrm{HPCN}$ is preferably hydrogenated over the $\mathrm{C}=\mathrm{C}$ bond of the molecule.

When HPCN was hy'drogenated to HCP (one $\mathrm{C}=\mathrm{O}$ bond hydrogenation). which occurred with $\mathrm{Pd} / \mathrm{C}(\mathrm{PD})$ or $\mathrm{Pd} / \mathrm{C}$ (IW) the reaction proceeded slowly and was not completed in 8 hours. On the other hand. all HPCN molecules were converted to BHDN (two $\mathrm{C}=\mathrm{C}$ bond hydrogenation) within 2 hours when the HPCN reacted with $\mathrm{Pd} / \mathrm{C}$ (Kawaken). The case when HPCN is converted to HCP rather than BHDN would be when hydrogen supply to the catalytic sites is not efficient. It is because only 2 moles of hydrogen are necessary to get $\mathrm{HCP}$ from $\mathrm{HPCN}$ while 4 moles of hydrogen are necessary to get BHDN. If the concentration of adsorbed hydrogen molecules is low. conversion to BHDN would be more severely hindered than that to HCP. In that case HPCN would be converted mainly to HCP and the reaction rate would be low due to low hydrogen concentration. which is the observed result with $\mathrm{Pd} / \mathrm{C}(\mathrm{TW})$ and $\mathrm{Pd} / \mathrm{C}(\mathrm{PD})$. This result may indicate that $\mathrm{Pd} / \mathrm{C}$ (Kawaken) has better hydrogen adsorption capability than $\mathrm{Pd} / \mathrm{C}(\mathrm{PD})$ or $\mathrm{Pd} / \mathrm{C}$ (IW). This possibility is also supported by an observation that it took only $\mathrm{l}$ hour for the total conversion of $\mathrm{BP}$ with $\mathrm{Pd} / \mathrm{C}$ (Kawaken) during hydrogenation of BP while it took 3 hours with the $\mathrm{Pd} / \mathrm{C}(\mathrm{PD})$. These results show that $\mathrm{Pd} / \mathrm{C}$ catalysts can invoke different reaction path in BP hydrogenation according to its preparation method and physical properties.

\section{Conclusions}

The catalyst prepared by precipitation and deposition method. $\mathrm{Pd} / \mathrm{C}(\mathrm{PD})$. was not effective in the conversion of $\mathrm{BP}$, but it was the most effective in enhancing the selectivity of $\mathrm{BHD} . \mathrm{Pd} / \mathrm{C}$ (PD) seems to have metal crystals mainly on the outer shell of carbon, which decreased the diffusional limitation of bulky intermediate molecules inside the porous support and enlanced their conversion to BHD. Pd/C (IW) seems to have acid left on the support yielding less BHD due to hydrogenolysis of BP.

The best preparation condition of $\mathrm{Pd} / \mathrm{C}(\mathrm{PD})$ to induce the highest selectivity of BHD was $60^{\circ} \mathrm{C}, 3 \mathrm{~mL} / \mathrm{min}$, and $\mathrm{pH} 11$ using reduction in the gas phase $\left(\mathrm{H}_{2}(\mathrm{~g})\right)$. Preparation conditions to give optimum metal distribution in the outer shell of support seem to invoke superior catalytic performances.

In BP hydrogenation, which is composed of a long series reaction. the major reaction route was changed depending on the kind of $\mathrm{Pd} / \mathrm{C}$ catalyst. The change in reaction route between $\mathrm{C}=\mathrm{O}$ bond hydrogenation (hydrogenation of HPCN to $\mathrm{HCP}$ ) and $\mathrm{C}=\mathrm{C}$ bond hydrogenation (hydrogenation of HPCN to BHDN) seems to depend on the catalyst s hydrogen delivery capability. With the catalysts prepared in the laboratory, the $\mathrm{C}=\mathrm{C}$ bond of $\mathrm{HPCN}$ reacted slowly owing to poor hydrogen delivery, and HPDN was mainly converted to $\mathrm{HCP}$, while with $\mathrm{Pd} / \mathrm{C}$ (Kawaken) $\mathrm{HPCN}$ was mainly converted to BHDN.

\section{References}

1. Noboru. Y.: Shizuo. N. JP Patent 1992. 279537.

2. Yasushi. I. JP Paten 2001.002616.

3. Wilds. A. L: Shunk. C. H:; Hoftman, C. H. J. Am. Chem. Soc. 1954. 76,1733

4. Cho. H.-B.; Lee J.C.: Park. Y.-H. Catal Todo, 2006. 111. 417.

5. Suh. D. I. Characteristics of Carbon Supported Palladim Catalusts for Liquid Phase Hydrogenation of Witho Aromatics. Ph.D thesis. 1991: pp I $(0) 1111$.

6. Geus. J. W. van Dillen. A. J. Handbook of Heterogeneous Catalysis: VCH: Germany. 1997; vol. 1, p 241.

7. Jhung, S. H.: Lee, J.-H.: Lee, J.-M.: Lee, J. H.: Hong. D.-Y; Kim. M.-W.: Chang. J.-S. Bull. Kor Chem. Soc. 2005. 26. 563.

8. Albers. P.: Bummeister. R.: Seibold. K.: Prescher. G.: Parker. S. F.: Ross. D. K. J. Catal. 1999. J81. 145.

9. Cybulski, A.: Moulijn. J. A.; Shanna M. M; Sheldon, R. A. Fine Chemicals Hanfacture-Techology and Engineering. Elsevier: Amsterdam. The Netherlands, 2001: $p 78$.

10. Sult. D. T.: Park. T.-T.: Ihm. S.-K. Carbon 1993. 31.427

11. Okhlopkova. L. B.: Lisitsyn. A. S.: Likholobov. V. A.: Gurath. M.: Boelun. H. P. Appl Catal. A: Gen. 2000. 204. 229.

12. Suh. D.-J.: Park, T.-J. Ind Eng. Chem. Res. 1992. 31, 1849.

13. Suh. D. J.: Park. T.-J.: Ihm, S.-K. J. Catal 1994, 149, 486.

14. Mohr. C.: Claus, P. Sci. Progress 2001, 84, 311. 